\title{
Executive summary of European Task Force document on diagnostic tools in rhinology*
} \author{
Passalacqua ${ }^{8}$, E. Toskala ${ }^{9}$, C.M. van Drunen ${ }^{5}$ \\ University Hospitals Leuven, Belgium \\ Royal National Throat, Nose and Ear Institute, London, United Kingdom \\ University Hospital Barcelona, Spain \\ University Hospital Ghent, Belgium \\ University Hospital Amsterdam, The Netherlands \\ University Hospital Rotterdam, The Netherlands \\ University Hospital Zagreb, Croatia \\ University Hospital of Genoa, Italy \\ Center for Applied Genomics, Philadelphia, USA
}

P.W. Hellings' 1 , G. Scadding², I. Alobid ${ }^{3}$, C. Bachert 4 , W.J. Fokkens 5 , R. Gerth van Wijk6, P. Gevaert ${ }^{4}$, J. Guilemany ${ }^{3}$, L. Kalogjera7, V.J. Lund², J. Mullol ${ }^{3}$, G.

Rhinology 50: 339-352, 2012

DOI:10.4193/Rhino 11.252

*Received for publication:

December 2, 2011

Accepted: April 25, 2012

\begin{abstract}
Summary
This Executive Summary of the EAACI Task Force document on Diagnostic Tools in Rhinology provides the readers with an overview of the currently available tools for diagnosis of nasal and sino-nasal disease, published in full version in the first issue of Clinical and Translational Allergy. A panel of European experts in the field of Rhinology have contributed to this consensus document on Diagnostic Tools in Rhinology. Important issues related to history taking, clinical examination and additional investigative tools for evaluation of the severity of nasal and sinonasal disease are briefly highlighted in this executive summary.
\end{abstract}

Key words: diagnosis, rhinology, allergic rhinitis, rhinosinusitis, history, examination, rhinoscopy, nasal patency

\section{Introduction}

There are several reasons for accurate investigation of upper airways disorders such as allergic rhinitis ${ }^{(1)}$ and rhinosinusitis (2). The first relates to the fact that such problems impact very significantly upon patients' quality of life and that well-directed treatment can ameliorate this impairment. The second is that some of these disorders are severe and systemic with significant morbidity, and that presentation often occurs in the upper airway. The third reason relates to the fact that upper respiratory tract problems exacerbate lower respiratory symptoms and may extend to involve the lower respiratory tract. The nose is an air conditioner; filtering, warming and humidifying over 10,000 liters of air daily before it progresses to the lungs.

This document aims to provide a brief summary of the methods used in Rhinology, including their applicability, specificity and sensitivity. 


\section{History of the patient}

The aim of history taking is to evaluate the presence, severity and duration of symptoms, in order to obtain an accurate diagnosis enabling adequate treatment. In rhinitis and rhinosinusitis, an accurate history is usually more important than any other investigation.

Allergic rhinitis is defined as having two of the listed symptoms for $>1$ hour/day for $>2$ weeks: blockage, running (including postnasal drip), sneezing and itching. Nasal problems are often multi-factorial in nature. History for AR should include specific questions related to timing and severity of symptoms, particularly nasal itching and ocular involvement, alleviating factors, seasonal aggravation, and signs of atopy in other organs. The diagnosis of allergic rhinitis (AR) is based upon the concordance between a typical history of allergic symptoms and diagnostic tests. Many AR subjects also have asthma. There is an association between rhinitis and OME in childhood ${ }^{(3)}$. Pharyngitis/laryngitis can occur secondary to rhinitis or may be the predominant feature. Food allergy is often associated with allergic airway disease and atopic dermatitis ${ }^{(4)}$.

In rhinitis patients who are not allergic, i.e. having negative skin prick test results or negative blood analysis for allergen-specific $\lg \mathrm{E}$, there is an extensive differential diagnosis. In small children with an adequate immune defence, up to 8 viral upper respiratory tract infections may occur per year, or adenoid hypertrophy may be associated with persistent rhinorrhoea and open mouth breathing. In adults, an extensive drug history may reveal overuse of topical alpha agonists or the possibility of aspirin or NSAID hypersensitivity. Hormonal rhinitis can occur, so questions about hormone therapy, possible thyroid auto-immunity, or pregnancy are needed. Atrophic rhinitis can be a primary condition at- tributed to Klebsiella ozaenae or secondary to excessive surgery or radiation. Neurogenic rhinitis is incompletely understood but is usually non-inflammatory. Old man's drip is thought to be hormonal since it responded to testosterone, before therapy with ipratropium bromide was found to be effective.

Rhinitis frequently co-exists with sinusitis, so the correct term in patients with symptomatic inflammation of the sinus cavities is rhinosinusitis. Rhinosinusitis, which can include nasal polyps $(\mathrm{NP})^{(2)}$, is defined as inflammation of the nose and the paranasal sinuses characterized by two or more symptoms, one of which should be either nasal blockage / obstruction / congestion or nasal discharge (anterior / posterior nasal drip), with or without facial pain/pressure, with or without reduction or loss of smell; plus either endoscopic signs of polyps / mucopurulent discharge / oedema / mucosal obstruction primarily in the middle meatus, and/or Computerised Tomography (CT) changes showing mucosal changes within the ostiomeatal complex and/ or sinuses.

The EP3OS document defines the disease according to the duration of symptoms:

Common cold/acute viral rhinosinusitis is defined as an acute rhinosinusitis lasting $<10$ days.

Acute (non-viral or bacterial) rhinosinusitis is defined by an increase in symptoms after 5 days or persistent symptoms after 10 days with $<12$ weeks duration.

Chronic rhinosinusitis/NP is defined symptoms for $>12$ weeks. The disease can be divided into MILD, MODERATE or SEVERE based on the total severity VAS score $(0-10 \mathrm{~cm})$ : MILD = VAS $0-$ 3; MODERATE = VAS $3.1-7$; SEVERE = VAS $7.1-10$.

Patients with rhinosinusitis should be asked for the specific

Table 1. Instruments used in allergic rhinitis and in chronic rhinosinusitis.

\begin{tabular}{|c|c|c|c|}
\hline & & Generic & Disease specific \\
\hline \multirow[t]{2}{*}{ Allergic rhinitis } & Children & & Pediatric RQLQ, adolescent RQLQ \\
\hline & Adults & $\begin{array}{l}\text { SF-36, SF-12, } \\
\text { 15D }{ }^{(7)} \text {, EuroQol 5D }\end{array}$ & $\begin{array}{l}\text { RQLQ, standardized RQLQ, mini-RQLQ, Nocturnal } \\
\text { Quality of Life Questionnaire (NQLQ) }{ }^{(8)} \text {, } \\
\text { Rhinitis Outcome Questionnaire }{ }^{(9)} \#, \\
\text { Rhinitis Symptom Utility Index (RSUI) }\end{array}$ \\
\hline \multirow[t]{2}{*}{ Chronic rhinosinusitis } & Children & $(\mathrm{CHQ})^{(10)}$ & SN-5 quality of life survey ${ }^{(11)}$ \\
\hline & Adults & $\begin{array}{l}\text { SF-36, SF-12, McGill pain questionnaire } \\
\text { (MPQ), EuroQol 5D, Glasgow benefit inven- } \\
\text { tory (GBI) }\end{array}$ & $\begin{array}{l}\text { Rhinosinusitis Outcome Measurement (RSOM- } \\
31)^{(12)} \text { \#, Rhinosinusitis Disability index (RSDI) \#, } \\
\text { sinonasal outcome test } 16 \text { (SNOT-16) }{ }^{(13)} \text { \#, SNOT- } \\
\text { 20\#, Chronic sinusitis survey (CSS) } \\
\text { Sinusitis outcomes questionnaire (SOQ) }{ }^{(16)}\end{array}$ \\
\hline
\end{tabular}


Figure 1. Evaluation of nasal valve dysfunction causing obstruction.
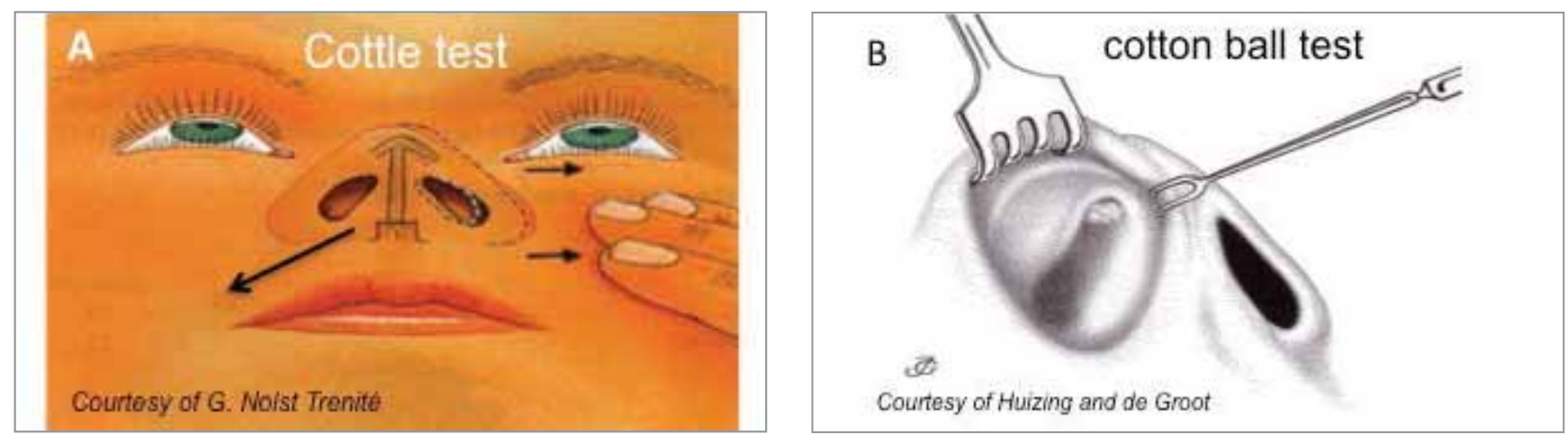

issues related to the onset, timing, severity of symptoms, provoking and alleviating factors, as well as seasonal aggravation, bronchial symptoms, and familial history of sinus disease.

\section{Recommendations}

Adequate time and attention should be given to take a complete and accurate history both of rhinitis symptoms and those of possible co-morbidities. The history should suggest further diagnostic tests needed for a proper diagnosis.

ENT referral is needed for unilateral nasal problems, nasal perforations, ulceration or collapse, sero-sanguineous discharge, severe crusting within the nasal cavity, recurrent infection, periorbital cellulitis (refer urgently), severe sleep problems.

\section{Quality of life instruments in rhinology}

The importance of quality of life issues in nasal disease has been well recognized. The effects of disease on daily functioning, work, leisure and school as perceived by the patient are considered as an important characteristic of rhinitis/ rhinosinusitis severity ${ }^{(1)}$. Moreover, assessment of quality of life is one of the standard outcome measures in clinical trials.

Generic questionnaires measure physical, psychological and social domains in all health conditions irrespective of the underlying disease. Those questionnaires allow the comparison between healthy and diseased subjects. Disease-specific instruments have been designed by asking patients what kind of problems they experience from their disease.

Clinicians should be able to estimate the burden of disease in their patients. A quality of life questionnaire might be helpful. Many HQLQ instruments however are developed for use in clinical trials. In a recent systematic review, 13 disease specific HQLQ tools for adults were evaluated ${ }^{(5)}$. Several questionnaires can be used in practice (Table 1). One questionnaire, the Rhinasthma ${ }^{(6)}$ evaluates patients with rhinitis and asthma.

\section{Recommendations}

The choice for a QoL instrument depends on its purpose and the target population. For purposes of research other questionnaires are needed than for the evaluation of patients in clinical practice. The use of both generic and specific instruments may be useful (17), although this may not be always the case. As the outcome of quality of life assessment is only partly associated with clinical outcome measures, it is recommended to evaluate patients with both HRQL and medical measures.

\section{Examination}

Nasal examination aims at finding any abnormality or disease that can explain the symptoms.

In the evaluation of a patient with (sino-)nasal symptoms, it is indispensable to start with a good inspection of the nose and face, both at rest as well as during inspiration. Initial observation of the patient may find clues to AR such as an allergic crease, Denny Morgan lines below the eyes, shiners under them or an allergic salute.

Nasal inspection can be supplemented by the mirror test to roughly estimate nasal patency.

Palpation of the nose allows the detection of pathology of the skin, the tissues, the bony and cartilaginous parts of the nose. Nasal valve dysfunction causing obstruction can be evaluated with the Cottle test (for external valve dysfunction) or cotton ball test (for internal valve dysfunction)(Figure 1). In case of lack of tip support, the tip elevation test may provide the examiner with valuable information on the cause of nasal obstruction. Anterior rhinoscopy makes a quick but limited internal inspection possible of the anterior parts of the cavum nasi, evaluating the presence of nasal discharge or mucosal swelling, crusting, septal perforations, and/or large polyps. Anterior rhinoscopy is limited in its evaluation of the entire nasal cavity. Posterior rhinoscopy allows the inspection of the posterior parts of the cavum nasi but is often replaced by nasal endoscopy. 


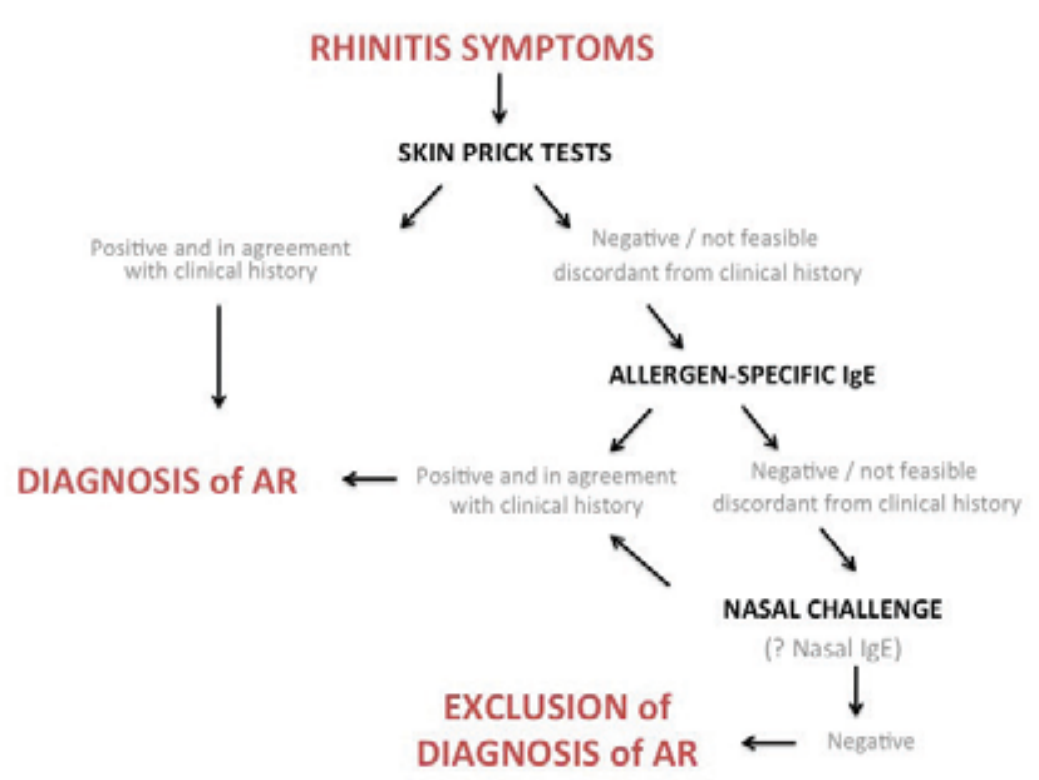

In comparison with the anterior and posterior rhinoscopy, nasal endoscopy offers the advantage of a global evaluation of the endonasal cavity. A good evaluation of the septum, the whole nasal cavity and the nasopharynx is possible, but also the area of the middle meatus, which has clinical importance in rhinosinusitis. Nasal endoscopy can be performed by a flexible or rigid scope that is attached by fibreoptic cable to a strong laser light source.

Transillumination of the maxillary or frontal sinus with a light source, also called diaphanoscopy, is only useful in case of a unilateral acute maxillary or frontal sinusitis of an adult patient, who did not yet undergo sinus surgery. The method was widely used for about half a century, but could not compete with modern techniques of radiography (18).

\section{Recommendations}

Inspection, palpation and anterior rhinoscopy are easy and rapid ways to examine a nasal problem without inconvenience to the patient. Therefore they should be the cornerstone of every physical examination, supplemented with nasal endoscopy in case of persistent symptoms or suspicion of rhinosinusitis.

\section{Allergy tests including provocation}

The main goal of the diagnostic tests in allergy is to demonstrate both the presence and functional relevance of allergen specific $\lg \mathrm{E}$. The presence of specific $\lg \mathrm{E}$ can be demonstrated either in vivo (skin tests, SPT) or in vitro by detecting allergen-specific lgE in the blood (RAST, CAP-RAST and equivalent assays). Currently, SPT are unanimously considered the gold standard and the first- line approach for the detection of allergic sensitization.

With a trained investigator SPT are highly reproducible $(19,20)$. Prick tests should be performed according to a rigorous methodology, with standardized diagnostic extracts, and always must include a negative (saline or diluent) and a positive control (histamine $\mathrm{HCl} 0.1 \%$ ). Weals $3 \mathrm{~mm}$ larger than the negative control are usually regarded as positive, but smaller ones may be relevant in children. Both false positive and false negative results can occur so the interpretation of a positive test must be integrated with the clinical history.

The first method used for the measurement of serum allergen specific IgE was the radioallergo-sorbent test (RAST) ${ }^{(21)}$. This has been now replaced by immune-enzymatic methods, including the widely used CAP-RAST assay. The level of specific $\lg E$ is expressed as $\mathrm{kU} / \mathrm{L}$, according to calibration curves, and the cutoff IgE level above which the test is positive is usually $0.35 \mathrm{KU} / \mathrm{l}$. The measurement of serum-specific lgE is usually slightly less sensitive but more specific than skin prick tests ${ }^{(22)}$.

Serum total $\lg E$ is measured using either radioimmunoassay or enzyme assay. In normal subjects, levels of IgE increase from birth to adolescence and then decrease to reach a plateau after the age of 20 - 30 years. Total IgE may also be increased in conditions such as smoking and parasitic diseases and may or may not be elevated in rhinitis. Total-serum IgE should not be used for screening or allergy diagnosis ${ }^{(1)}$. Where IgE tests do not provide a diagnosis yet allergy is suspected, local IgE should be 
Table 2. Different diagnostic smell tests currently available.

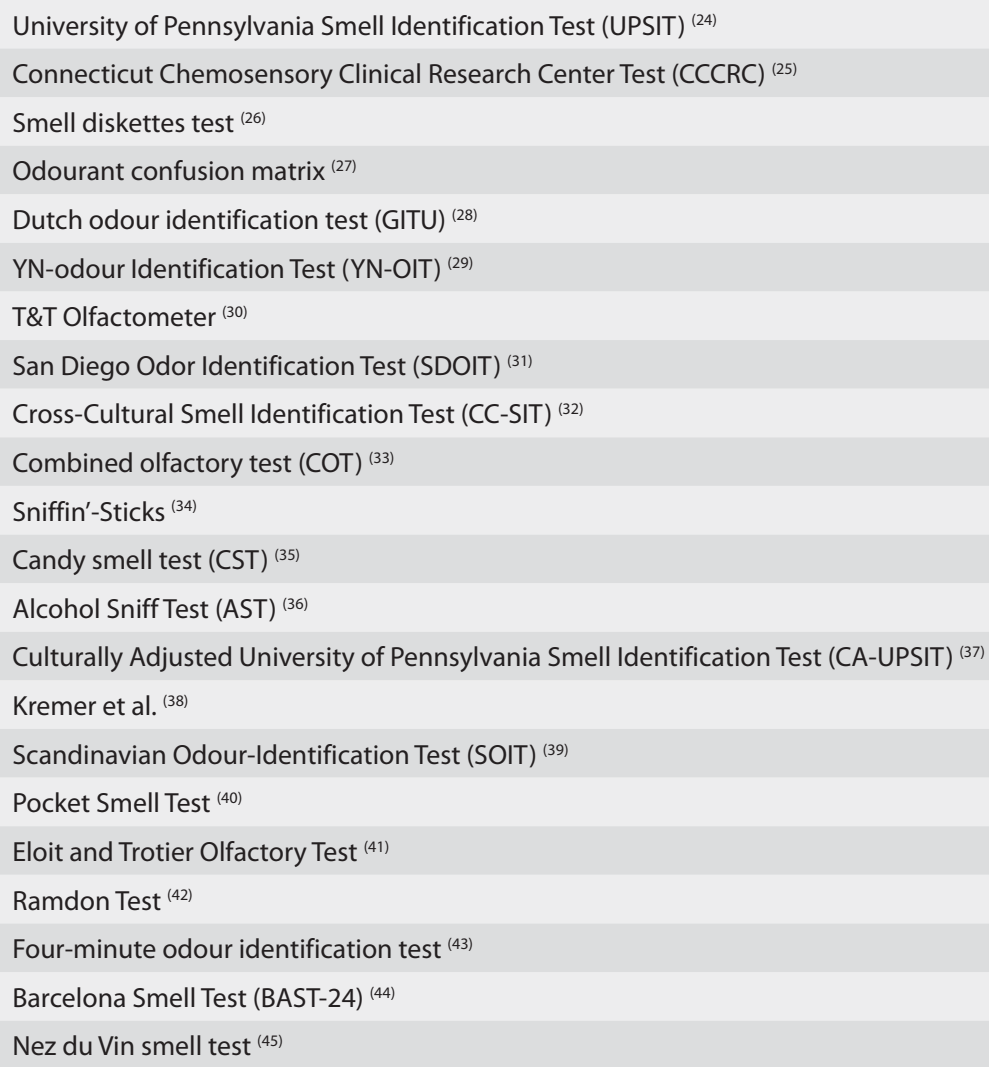

sought by allergen - specific nasal challenges (ASNC). Figure 2 shows a diagnostic algorithm for allergic rhinitis.

These are also known as specific nasal provocation test (SNPT) or nasal allergen challenge (NAC) involves the delivery of a small quantity of the allergen into one (or both) nostril(s), in order to elicit an allergic reaction if allergen-specific $\lg E$ is present in the nasal mucosa. By using progressively increasing amounts (or concentrations) of the allergen, a threshold dose can be established. The main indications of ASNC are to demonstrate the causal role of an allergen, to identify the clinically relevant allergen(s) in poly-sensitized subjects, to evaluate the effects of a treatment, to study inflammatory phenomena, and to evaluate the role of occupational allergens.

The nasal challenge with aspirin is not an allergen challenge, since an lgE mediated mechanism is not involved. Nevertheless it is used to diagnose aspirin intolerance in the context of aspirin hypersensitivity with respiratory manifestations. The nasal challenge with aspirin was introduced later than the oral and bronchial challenge ${ }^{(23)}$, and can be used in patients with severe asthma in whom oral or bronchial aspirin challenges are contraindicated.

Nasal hyper-reactivity is the capacity of the nasal mucosa to res- pond with clinical symptoms and inflammation to non-specific stimuli, which do not cause any mucosal reaction in normal subjects. These stimuli may directly act on a single receptor such as histamine, adenosine monophosphate, and methacholine, or activate a more complex mechanism, such as mannitol, capsaicin, hyperosmolar solutions and cold air.

Figure 3 shows the basis of nasal challenge tests.

\section{Recommendations}

Allergy diagnosis should be based on a suggestive clinical history, clinical examination and demonstration of relevant sensitization, preferably using SPT. Upon specific indications, blood testing and/or NAC are advocated.

\section{Assessing the sense of smell}

Patients with rhinitis and/or rhinosinusitis may have olfactory dysfunction of varying degrees. Assessment of smell is helpful in identifying more severe disease, especially nasal polyps, and in monitoring the response to therapy. Several techniques are currently available for the objective evaluation of an individual's smell capacity, with each test having its own strengths and weaknesses that are dealt with extensively in the full document published in Clinical Translational Allergy. 
MRI can be used to assess the olfactory bulb as well as to investigate possible neoplasms causing hyposmia/ anosmia. Olfactory evoked potentials are at present largely a research tool.

\section{Recommendations}

Smell testing should be an integral part of the diagnostic approach in patients with smell dysfunction, i.e. hyposmia, parosmia or anosmia as presenting symptoms of sino-nasal disease, posttraumatic or post-viral smell disorder. It should also be used in initial assessment of rhinitis / rhinosinusitis and in response to treatment.

\section{Assessing the sense of taste}

Smell disorders may be associated with disturbed taste capacity, hence necessitating the evaluation of the five basic taste sensations, i.e. salt, bitter, sour, umami and sweet, in addition to smell capacity in these patients.

Gustometry with application of taste substances and electrogustometry are the methods of taste examination. The stimuli used in gustometry are: citric acid or hydrochloric acid (sour), caffeine or quinine hydrochloride (bitter), sodium chloride (salt), saccharose (sweet), monosodium glutamate (umami). Electrogustometry allows estimation of the functioning of taste by means of electric excitability thresholds determined through the response to the irritation of taste buds with electrical current of different intensities. Electrogustometry is especially useful in estimating the efficiency of sensory pathways.

\section{Recommendations}

Testing the taste capacity represents a diagnostic tool that is helpful in the clinical discrimination of smell and taste disorder in patients with smell problems complaining of combined loss of smell and taste, and in patients with isolated taste disorders.

\section{Nasal nitric oxide}

Measurement of nasal NO ( $\mathrm{nNO}$ ) may represent a useful tool for research purposes as well as for screening for Primary Ciliary Dyskinesia in which it is particularly low. Nasal nitric oxide may be normal, raised or lowered in other disease states and correlate with the degree of nasal polyposis. Measuring both bronchial and nasal nitric oxide may assist the combined management of upper and lower airways.

As for exhaled NO (eNO), nasal (nNO) can be measured by chemiluminescence. Guidelines for measurement have been published ${ }^{(46)}$. In contrast to measuring eNO, high baseline levels in nNO make background environmental NO levels less of a problem. Conversely, there is a high degree of inter-individual variability amongst healthy controls and a significant degree of intra-individual variation over time ${ }^{(47)}$.

\section{Recommendations}

Nasal NO is a useful measure to alert the clinician to a possible defect in mucociliary clearance (PCD, CF) and may have a role in the evaluation of the patency of the sinus ostium.

\section{NASAL SAMPLING}

Lavages, cytology, biopsies

Nasal sampling is performed in order to gain information on the inflammation and cell contents in the nasal / sino-nasal cavity in patients with rhinitis / rhinosinusitis.

Figure 3. Practical approaches to nasal provocation testing.

\section{Provocation tests}

STIMULUS

Allergen

Histamine

Metacholine

Hyperosmolar solution

Adenosine

Mannitol

\section{DELIVERY}

Powder

Solution

Paper disks

Aerosol
OUTCOMES

Symptom scores

Aspect of mucosa

Weight of secretions

Number of sneezes

Nasal flow

Cytology

Mediators

Nitric Oxide 
Table 3. Comparison of different techniques.

\begin{tabular}{|c|c|c|}
\hline Method & Advantage & Disadvantage \\
\hline Nasal blown secretions & - easy to perform & $\begin{array}{l}\text { - subject must be able to blow nose } \\
\text { - no information about mucosa }\end{array}$ \\
\hline Nasal lavage & $\begin{array}{l}\text { - easy to perform } \\
\text { - luminal proteins, cells, mediators and cytokines }\end{array}$ & $\begin{array}{l}\text { - reliability depends ability of subject to } \\
\text { close nasopharynx } \\
\text { - dilution of mediators and cytokines } \\
\text { - variable recovery of fluid } \\
\text { - no information about mucosa }\end{array}$ \\
\hline Sinus packs or filter paper & - no/limited dilution of mediators & $\begin{array}{l}\text { - may irritate the nose } \\
\text { - cannot collect cells } \\
\text { - no information about mucosa } \\
\text { - more difficult than lavage }\end{array}$ \\
\hline Microsuction technique & - no dilution of mediators & $\begin{array}{l}\text { - representative sample? } \\
\text { - technically difficult } \\
\text { - cannot collect cells } \\
\text { - no information about mucosa }\end{array}$ \\
\hline Nasal brush & - sample of epithelium & $\begin{array}{l}\text { - no sample of deeper layers } \\
\text { - no information about nasal lumen } \\
\text { - technically more difficult }\end{array}$ \\
\hline Nasal scraping & - sample of epithelium & $\begin{array}{l}\text { - no sample of deeper layers } \\
\text { - no information about nasal lumen } \\
\text { - technically more difficult }\end{array}$ \\
\hline Nasal biopsy & - sample of total nasal mucosa & $\begin{array}{l}\text { - no information about nasal lumen } \\
\text { - technically difficult }\end{array}$ \\
\hline
\end{tabular}

Secretions in the nasal airways can be blown onto wax paper or a plastic wrap and then placed onto a glass slide. Microscopic evaluation allows the discrimination of epithelial cells from granulocytes. Eosinophils are identifiable by staining.

Nasal lavage is the introduction of fluid into the nasal cavity and its recovery after a dwell time. Nasal lavage allows the evaluation of the content of the secretions in the nasal lumen such as protein, cells, mediators and cytokines. The consistency of the findings in allergic and infective rhinitis for a range of different measures in nasal lavage fluid supports the concept that this method of nasal evaluation provides reliable information of relevance to disease activity although normalization of the variable recovery can be difficult.

Pre-weighed sinus packs or filter papers can be placed on the floor of the nasal cavity between the septum and inferior turbinate for $5 \mathrm{~min}$ and then placed back in a Falcon tube. In order to mobilize the nasal secretions out of the sinus pack, the sinus pack is washed with $3 \mathrm{ml}$ of $0.9 \% \mathrm{NaCl}$ solution. The sinus pack is then placed into the shaft of a syringe and the sinus pack is squeezed by moving the piston of the syringe. After this first pressure the shaft containing the sinus pack is placed into a Falcon tube and centrifuged at 1,500 $\mathrm{g}$ for $10 \mathrm{~min}$ to recover all fluid.
Nasal secretions can be collected by direct aspiration using microsuction tubes ${ }^{\left({ }^{(48)}\right.}$. The samples can be collected by repeated aspiration into a pre-weighed plastic sampling tube immediately followed by aspiration of a known volume $(1.0 \mathrm{ml})$ of PBS containing $10 \%$ of Mesna. The direct aspiration system combines the advantages of minimal irritation of the nasal mucosa with the facility to determine concentrations per gram of secretion.

A small nylon brush used can be introduced in the middle meatus of the nose and turned carefully. The brush is immediately placed in a $5 \mathrm{ml}$ polystyrene plastic tube containing $5 \mathrm{ml}$ of PBS and is cut off just above the bristles. The brush can then be shaken vigorously in the solution and carefully brushed off against the wall of the tube. The tubes are centrifuged at $400 \mathrm{~g}$ for 10 minutes ${ }^{(49)}$. Nasal brushing gives information on living epithelial cells, which is an advantage over nasal lavage. Brushing can reliably be used in babies and small children ${ }^{(50)}$.

Nasal scraping can be performed with the Rhinoprobe ${ }^{(51,52)}$. The cupped tip of the disposable probe is gently passed over the mucosal surface of the medial aspect of the inferior turbinate. Two or three short scrapes of the epithelial layer are made to obtain a sample. The specimen is spread onto a plain slide and immediately fixed for at least 1 minute in 95\% ethyl alcohol. Nasal scrapings give information on living epithelial cells some- 
Figure 4. Diagnostic algorithm for occupational rhinitis.

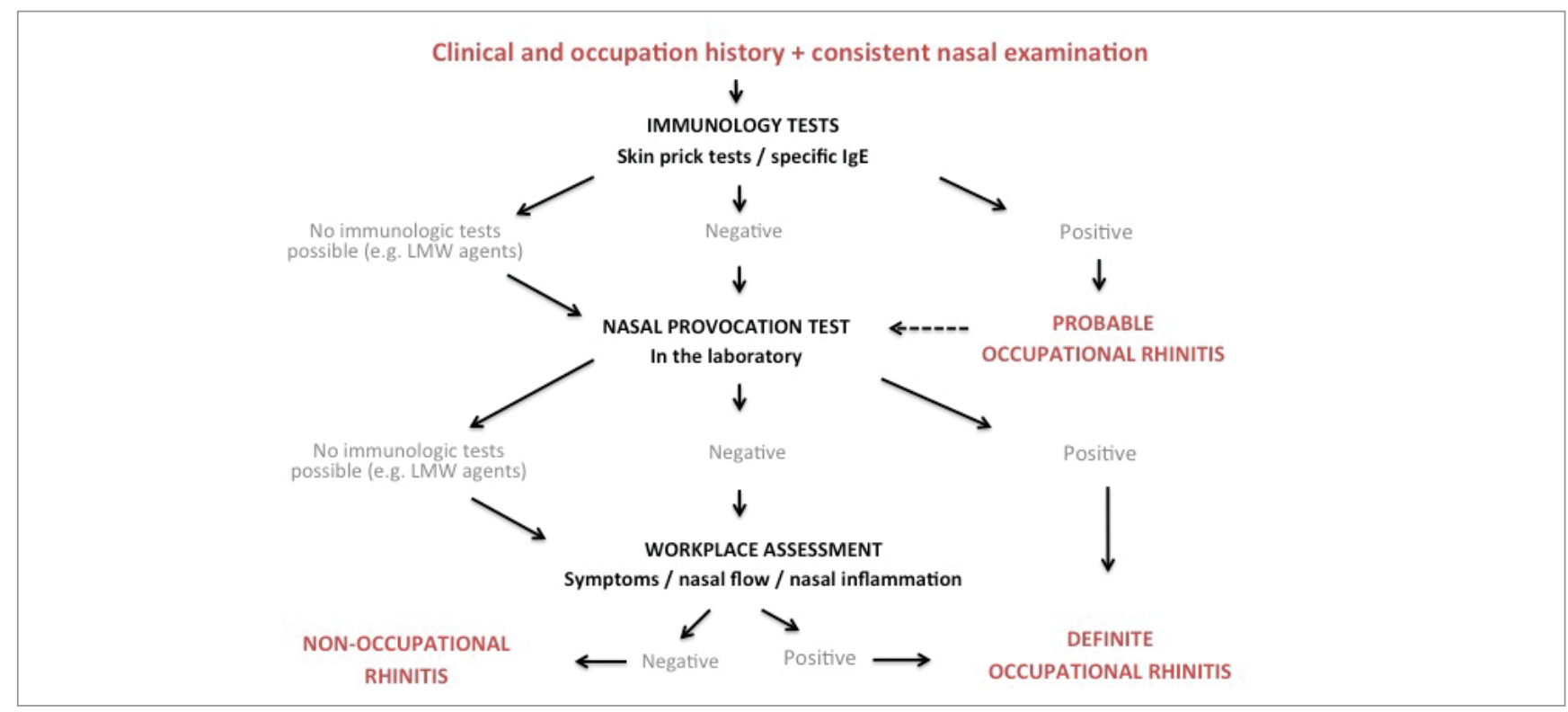

Table 4. Clinical use and indications.

\section{PNIF}

Diagnostic purposes

- unilateral disease

- correlation with syptoms
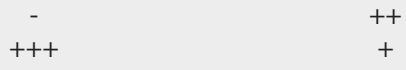

$+$

Use in children

2- $6 y$

$6-18 y$

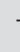

$+$

$++$

$+++$

$+++$

Provocation studies

Clinical trials

$+++$

$+++$

Home monitoring

$+++$

$+++$

$+++$

$+++$

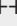

$+++$

$+++$

$++$

$+++$ times in larger lumps.

Finally, biopsy specimens can be taken from the nasal mucosa, usually from the inferior turbinate. High quality $2.5-\mathrm{mm}$ biopsy specimens can be taken under direct vision with nasal biopsy forceps, such as Gerritsma forceps (Fokkens' forceps) ${ }^{(53)}$. Local anaesthesia is advised.

\section{Evaluation of nasal patency}

Objective evaluation of nasal obstruction is warranted in patients complaining of nasal blockage or for evaluation of mucosal changes in provocation studies or clinical trials.
Nasal patency can be monitored objectively by measuring the following parameters:

1. nasal air flow passing through the nose during nasal respiration, evaluated with the nasal peak inspiratory and expiratory flow (PNIF and PNEF)

2. the cross sectional area or volume of the nasal cavity evaluated with acoustic rhinometry and

3. the nasal airflow and pressure during nasal respiration evaluated with rhinomanometry.

The PNIF is a validated technique for the evaluation of nasal flow through the nose. Nasal inspiration correlates most with the subjective feeling of obstruction and is the best validated 
technique for monitoring nasal flow in clinical trials and after nasal provocation ${ }^{(54)}$. The Youlten peak flow meter (Clement Clark International) is attached to anaesthesia mask, with nasal flow being expressed in litres $r$ per minute.

Active anterior rhinomanometry represents a physiologic measure of nasal airflow and pressure during normal inspiration and expiration. It is considered the standard technique for the evaluation of nasal airflow resistance, hence providing a functional measure of nasal patency.

Acoustic rhinometry is a non-physiologic measure of nasal patency, measuring echoes of sound impulses sent into one nostril. The measurement provides information on the nasal luminal anatomic structures, either as a measure of nasal volume over a standard distance into the nostril or as the minimal cross-sectional area within the nasal cavity. The measurement is performed in each nasal cavity separately.

Anterior rhinoscopy allows the examiner to evaluate the anterior half of the nasal cavity. The subjective evaluation of nasal patency by the appreciation of the endonasal lumen, anatomic relationships and mucosal disease is an important diagnostic tool for the evaluation of nasal patency. In posterior rhinoscopy, choanal openings and mucosal disease at the nasopharynx are evaluated. In experienced hands, this technique may be helpful but nasal endoscopy is superior.

Holding a cold metallic spatula or mirror under the nose during expiration allows the examiner to evaluate the condensation of exhaled air onto the metal device, called the mirror test. It can be useful as a screening tool for evaluation of nasal patency in children. This test of limited diagnostic value in the evaluation of nasal congestion.

\section{Recommendations}

Depending on the specific aim of nasal patency and flow evaluation, one may rely on different tools for the evaluation of nasal patency and flow. In Table 4 the clinical use and indications are indicated.

\section{Microbiology}

Chronic rhinosinusitis is defined as inflammation of the nose and sinuses and the diagnosis is based on characteristic symptoms lasting for more than 12 weeks. The definition does not imply infection as the etiological cause. There is no evidence that microbiological assessment of nasal or sinus samples has any impact on outcomes in rhinitis / rhinosinusitis.

Nasal and sinus samples for microbiological assessment are taken as swabs, aspirates, lavages or biopsies. Maxillary sinus samples can be taken through inferior meatal puncture, transoral puncture or endoscopically guided through the middle meatus. Correlation of endoscopically taken samples from maxillary sinuses, compared to maxillary sinus puncture is high in most of the studies ${ }^{(55)}$.

Routine bacteriological analyses of the samples are based on cultivation on selective plates and phenotyping and identification of gram positive, gram negative and anaerobic bacteria. For the detection of intracellular bacteria, immunohistochemistry may demonstrate a specific bacterial strain in mucosal tissue. Detection and amplification of microbial RNA and DNA has improved detection sensitivity, but does not give information on microbial viability. Real-time quantitative polymerase chain reaction (RT-PCR) may give information of the number of bacteria, but sequential samples are needed to prove viability. For the detection of bacteria in biofilm (56), fluorescent in situ hybridization (FISH) is usually applied, coupled with confocal microscopy.

\section{Recommendation}

Microbiological assessment is not to be used routinely in diagnosis of rhinitis / rhinosinusitis. Acute rhinosinusitis non-responsive to empirical antimicrobial treatment and topical nasal steroids should be referred to an ENT specialist, where further diagnostic procedures, including microbiology, should be done.

\section{Evaluation of mucociliary clearance}

Normal mucociliary transport is essential for the maintenance of healthy sinuses. In case of infection and/or congenital dysfunction of the cilia asin primary ciliary dyskinesia (PCD) (57), the mucociliary transport is inadequate or absent. In chronic inflammation, mucostasis, hypoxia, microbial products, toxic inflammatory mediators may induce secondary ciliary changes, i.e. secondary ciliary dyskinesia (SCD), with inadequate mucociliary transport.

The saccharine test evaluates the time a patient takes to notice a sweet taste after placement of a 1 - $2 \mathrm{~mm}$ particle of saccharine on the inferior turbinate mucosa $1 \mathrm{~cm}$ from the anterior end. Alternatively, one can monitor the time needed for a dye like methylene blue to be transported from the mucosa of the anterior third of the nasal cavity towards the hypopharynx. Other substances like technetium-99 m-labeled iron oxide have also been used. The mucociliary clearance time is considered to be normal below 15 minutes, and should be less than 1 hour. This test has limited diagnostic value due to its low sensitivity and specificity ${ }^{(57)}$.

Harvesting epithelial cells is performed by scraping along the inferior and middle turbinates by the use of a sterile cytology brush. These epithelial cells can be used for either structural investigation of the cilia of nasal epithelial cells with electron 
microscopy or for measuring ciliary beat frequency ${ }^{(58)}$. Electron microscopic evaluation of harvested epithelial cells may aid in the diagnosis of PCD, but is not $100 \%$ sensitive or specific.

Epithelial cells can be evaluated for ciliary beat frequency (CBF) and the ciliary waveform analyzed in detail by digital high-speed video imaging. The demonstration of normal CBF and beat pattern excludes the diagnosis of PCD.

The evaluation of ciliogenesis in vitro constitutes the gold standard for diagnosis of PCD, allowing the differentiation between primary and secondary ciliary dyskinesia. This technique is time-consuming, and only available in a limited number of academic centres world-wide.

\section{Recommendations}

No ideal test is available for the diagnosis of PCD. In case of suspicion of $P C D$, one should consider diagnostic tests of ciliary function by evaluation of $C B F$, electron microscopic evaluation of the dynein arms of the cilia, and/or evaluation of the cilia after ciliogenesis in vitro. Measuring nasal NO levels represent a good screening tool for PCD.

\section{BLOOD AND ADDITIONAL TESTS}

Blood analyses including tests for allergen-specific IgE have been dealt with in the section on allergy testing. In severe non-infectious, non-allergic rhinitis, one may consider full blood count, including eosinophils, thyroid function, thyroid auto- antibodies, anti- nuclear antibodies, extractable nuclear antibodies (anti- Ro and anti-La are usually positive in Sjogren's syndrome), pregnancy test or tests for drugs of addiction on urine.

Depending on the clinical history and examination, the following analyses should be considered in CRS without NP:

- full blood count including differential white cell count, ESR and/or C Reactive Protein

- evaluation of renal, liver and thyroid function

- humoral immunity markers: immunoglobulins, IgG subclasses, specific antibody levels to tetanus, Haemophilus, Pneumococcus and response to immunization if low

- cellular immunity markers: T and B cell numbers and ratios

\section{- HIV status}

- $\quad$ Angiotensin converting enzyme (ACE) is usually upregulated in macrophage activation in diseases such as sarcoidosis and tuberculosis

- c-ANCAs (anti- neutrophil cytoplasmic antibodies) are raised in Wegener's granulomatosis, in $60 \%$ of patients where upper respiratory tract alone is involved
Some specific pathologic entities should be considered in severe nasal polyp disease and require additional investigations. 1) Churg Strauss syndrome (CSS): Anti-neutrophil cytoplasmic antibodies (ANCA) are predominantly lgG autoantibodies directed against constituents of primary lysosome granules of neutrophils and monocytes. Several antigenic targets exist those ANCA directed to proteinase 3 or myeloperoxidase are clinically relevant.

2) Aspirin sensitivity: The oral and bronchial aspirin provocation tests may be associated with severe adverse reactions and alternative procedures with a higher safety profile are highly desirable. The nasal aspirin challenge is much safer, but if negative an oral challenge should be performed. Although the cellular antigen stimulation test (CAST) has been proposed as an alternative a recent study using CAST to measure cys LTs pre and post challenge showed that although the leukocytes of patients with aspirin sensitivity produce higher amounts of Cys-LTs the assay had a sensitivity of $25 \%$, a specificity of $92.3 \%$, and positive and negative predictive values of $28.7 \%$ and $90.7 \%$, respectively. The low sensitivity and predictive values limit the clinical usefulness of this test ${ }^{(59)}$.

3) Cystic Fibrosis (CF): The diagnosis of CF is suspected in case of severe CRS with NP and thickened secretions, hypoplasia of the paranasal sinuses, in association with recurrent bronchopulmonary infections. Blood analysis for CF trans membrane conductance regulator (CFTR) gene mutations may demonstrate homozygote and heterozygote gene mutations in a subgroup of CF patients ${ }^{(60)}$. The sweat test remains the gold standard for diagnosis of $C F$, as it is non-invasive, cheap and painless, with high sensitivity and specificity.

\section{Recommendations}

Blood analysis may be an alternative for skin prick test in patients suspect of allergic rhinitis. Blood analysis is advocated in the case of severe and therapy-resistant rhinosinusitis with/ without nasal polyp disease.

\section{Imaging in rhinology}

The aims of radiologic imaging are the demonstration of the source of individual sino-nasal symptoms, the extent of the sino-nasal disease, the relation of the sino-nasal problem with surrounding structures and the evaluation of the sino-nasal anatomy prior to sinus surgery.

Plain film radiographs in standard projections provide little information on disease extent and no information on sinus anatomy. In children with clinical suspicion of adenoid hypertrophy, lateral plain X-ray images may show adenoid hypertrophy.

CT scanning has become the most important imaging modality and helped the development of endoscopic surgery of the 
sinuses and skull base. Coronal sections have been the most requested plane on $\mathrm{CT}$ imaging of the nose and sinuses as this closest resembles the surgical anatomy encountered in endoscopic sinus surgery. Reconstruction of CT scans in coronal, axial and sagittal planes, enables excellent surgical planning nowadays. Certain features aid diagnosis: e.g. high metallic signals are associated with allergic fungal sinusitis, the reversed $C$ sign is found in cystic fibrosis.

Although more time consuming and costly, the use of MRI is recommended in patients with complicated inflammatory sinus disease extending beyond the boundaries of the sino-nasal cavities and/or in patients with suspected neoplasms. MRI should also be performed in most of the cases of unilateral sinus disease to allow the differential diagnosis of an inverted papilloma and sinus retention or to make the differential diagnosis between inflammatory lesion and expanding process. MRI scans are also being useful in delineating the olfactory bulb in anosmia. Ultrasonography of the paranasal sinuses is easily available, cheap and quick, with no irradiation or discomfort involved. However, it provides little information on disease extent, and has low sensitivity and specificity.

\section{Recommendations}

There is no evidence to support the use of imaging in uncomplicated acute rhinosinusitis. In CRS, CT scans confirm the clinical diagnosis where nasal endoscopy is not available and provide information on the extent of the disease.

\section{Diagnosis of occupational rhinitis (or)}

This is based on very careful and detailed medical history and history of exposure conditions at work (61). A distinction is made on rhinitis caused by agents (either allergens or low molecular weight compounds) in the working environment, i.e.
$\mathrm{OR}$, and rhinitis exacerbated by the work environment, i.e. workexacerbated rhinitis ${ }^{(61)}$.

A routine ENT examination including nasal endoscopy should be performed. Skin prick test and/or specific IgE tests for common aeroallergens and work related allergens and chemicals are mandatory. Common aeroallergens are tested to exclude their role and show if the patient is atopic already. If lower airway symptoms like cough, wheezing, dyspnoea or diminished ability for physical strain exist, additional spirometry and other examinations to exclude asthma are needed. In addition, use of any medication and other airway or systemic diseases possibly relating to the symptoms should be recorded.

Both nasal as well as bronchial challenge tests can be applied for the diagnosis of OR (Figure 4). Nasal challenge tests are the standard diagnostic tool to confirm the causative role of a specific agent in the development of rhinitis symptoms ${ }^{(62)}$. In addition to the scoring symptom severity, quantification of nasal flow have been included (cfr supra), as well as measurement of quantity and content of secretions. Sham provocation tests should be used to confirm the positive reaction with occupational exposure and exclude general nasal hyper-reactivity.

\section{Recommendations}

The diagnosis of occupational rhinitis is based on the patients' history. Allergic OR should be dealt with diagnostically like any other allergic rhinitis, whereas non-allergic occupational disease requires more specific attention. In case of important socio-economic impact of the diagnosis of $\mathrm{OR}$, the diagnosis can be confirmed by provocation tests that need to be performed in a standardized way involving subjective as well as objective evaluation of inflammation. 


\section{Concluding recommendations}

\begin{tabular}{|c|c|c|c|}
\hline & AIMS & METHODS / INSTRUMENTS & RECOMMENDATIONS \\
\hline HISTORY & $\begin{array}{l}\text { Evaluation of } \\
\text { * patients' symptoms and symptom severity } \\
\text { * co-morbidities and general medical condition } \\
\text { * medical / surgical history } \\
\text { * exposure to allergens / irritants } \\
\text { * cigarette smoke }\end{array}$ & $\begin{array}{l}\text { * Personal communication } \\
\text { * Questionnaires }\end{array}$ & $\begin{array}{l}\text { Essential part of diagnostic process } \\
\text { In all patients with nasal problems.... } \\
\text { and in those with lower respiratory tract } \\
\text { disease! }\end{array}$ \\
\hline QoLTOOLS & $\begin{array}{l}\text { Evaluation of the impact of nasal disease on } \\
{ }^{*} \text { quality of life } \\
{ }^{*} \text { different domains of physical and mental func- } \\
\text { tioning }\end{array}$ & $\begin{array}{l}\text { * Generic } \\
\text { * Disease-specific }\end{array}$ & $\begin{array}{l}\text { Helpful in clinical practice and clinical } \\
\text { trials }\end{array}$ \\
\hline $\begin{array}{l}\text { NASAL } \\
\text { EXAMINATION }\end{array}$ & $\begin{array}{l}\text { Evaluation of the } \\
{ }^{*} \text { external and endonasal anatomy } \\
{ }^{*} \text { endonasal mucosa and lumen }\end{array}$ & $\begin{array}{l}\text { * Inspection } \\
\text { * Palpation } \\
\text { * Ant. and post. rhinoscopy } \\
\text { * Nasal endoscopy }\end{array}$ & $\begin{array}{l}\text { * Non-ENT doctors should examine the } \\
\text { nose including ant. rhinoscopy } \\
{ }^{*} \text { A nasal endoscopy is recommended in } \\
\text { chronic rhinologic disease }\end{array}$ \\
\hline ALLERGY TEST & $\begin{array}{l}\text { Evaluation of the sensitization state, } \\
\text { including the demonstration of the specific sensi- } \\
\text { tization state }\end{array}$ & $\begin{array}{l}\text { * Skin prick test } \\
\text { * Blood analysis with allergen- } \\
\text { specific lgE }\end{array}$ & $\begin{array}{l}\text { Recommended in all patients with clini- } \\
\text { cal suspicion of allergic AW disease }\end{array}$ \\
\hline $\begin{array}{l}\text { NASAL } \\
\text { PROVOCATION } \\
\text { TEST }\end{array}$ & $\begin{array}{l}\text { Evaluation of the response of the nasal mucosa to } \\
\text { * allergens } \\
\text { * aspirin } \\
\text { * occupational agents }\end{array}$ & $\begin{array}{l}\text { Provocation by inhalation, } \\
\text { spray, nasal drop or discette }\end{array}$ & $\begin{array}{l}\text { Recommended in case of doubt about } \\
\text { sensitization }\end{array}$ \\
\hline SMELL TEST & Evaluation of the smell capacity & $\begin{array}{l}\text { Different tests are currently } \\
\text { available }\end{array}$ & $\begin{array}{l}\text { Recommended in case of severe hypos- } \\
\text { mia or anosmia }\end{array}$ \\
\hline TASTE TEST & Evaluation of taste capacity & Electrogustometry & $\begin{array}{l}\text { Recommended in patients with taste } \\
\text { dysfunction }\end{array}$ \\
\hline $\begin{array}{l}\text { NASAL PAT- } \\
\text { ENCY MEAS- } \\
\text { UREMENTS }\end{array}$ & $\begin{array}{l}\text { Evaluation of a patients' capacity to breathe } \\
\text { through the nose }\end{array}$ & $\begin{array}{l}\text { * PNIF } \\
\text { *Anterior rhinomanometry } \\
{ }^{*} \text { Acoustic rhinometry }\end{array}$ & $\begin{array}{l}\text { Recommended parameter in clinical trials } \\
\text { Helpful in clinical practise to evaluate the } \\
\text { evolution of nasal patency }\end{array}$ \\
\hline $\begin{array}{l}\text { NO MEASURE- } \\
\text { MENTS }\end{array}$ & Evaluation of $\mathrm{NO}$ levels in nasal cavity & $\begin{array}{l}\text { Chemiluminiscence reaction of } \\
\text { expired air }\end{array}$ & Helpful as screening tool in PCD \\
\hline $\begin{array}{l}\text { BLOOD AND } \\
\text { ADDITIONAL } \\
\text { TESTS }\end{array}$ & $\begin{array}{l}\text { Evaluation of the sensitization state, immune sys- } \\
\text { tem, endocrine system } \\
\text { Evaluation of mucociliary function }\end{array}$ & $\begin{array}{l}\text { * Blood test } \\
{ }^{*} \text { MCT, nasal NO, EM, ciliogen- } \\
\text { esis in vitro } \\
\text { * Sweat test }\end{array}$ & $\begin{array}{l}\text { Recommended as diagnostic tool in } \\
\text { severe rhinitis, rhinosinusitis and nasal } \\
\text { polyp disease with suspicion of underly- } \\
\text { ing auto-immune, immunologic or ciliary } \\
\text { disease }\end{array}$ \\
\hline $\begin{array}{l}\text { NASAL SAM- } \\
\text { PLING }\end{array}$ & $\begin{array}{l}\text { Collection of nasal mucosa / cells / secretions for } \\
\text { analysis }\end{array}$ & $\begin{array}{l}\text { * Nasal secretions } \\
\text { * Nasal scraping } \\
{ }^{*} \text { Nasal biopsy }\end{array}$ & $\begin{array}{l}\text { Recommendations: } \\
\text { * nasal sampling in experimental / clinical } \\
\text { studies } \\
{ }^{*} \text { nasal secretions for B2 transferrin analy- } \\
\text { sis in suspicion of CSF leak } \\
\text { * biopsy in case of unilateral / malignant } \\
\text { disease }\end{array}$ \\
\hline
\end{tabular}




\section{References}

1. Bousquet J, Khaltaev N, Cruz AA, et al. Allergic Rhinitis and its Impact on Asthma (ARIA) 2008 update (in collaboration with the World Health Organization, GA(2)LEN and AllerGen). Allergy. 2008; 63 Suppl 86: 8-160.

2. Fokkens WJ, Lund VJ, Mullol J. European position paper on rhinosinusitis and nasal polyps. Rhinology. 2012; Suppl. 23: 1-299.

3. Hellings PW, Fokkens WJ. Allergic rhinitis and its impact on otorhinolaryngology. Allergy. 2006; 61: 656-664.

4. Bousquet J, Van Cauwenberge P, Khaltaev N. Allergic rhinitis and its impact on asthma. J Allergy Clin Immunol. 2001; 108 (5 Suppl): s147-334.

5. van Oene CM, van Reij EJ, Sprangers MA, Fokkens WJ. Quality-assessment of diseasespecific quality of life questionnaires for rhinitis and rhinosinusitis: a systematic review. Allergy. 2007; 62: 1359-1371.

6. Baiardini I, Pasquali M, Giardini A, et al. Rhinasthma: a new specific QoL questionnaire for patients with rhinitis and asthma. Allergy. 2003; 58: 289-294.

7. Sintonen $\mathrm{H}$. The $15 \mathrm{D}$ instrument of healthrelated quality of life: properties and applications. Ann Med. 2001; 33: 328-336.

8. Juniper EF, Rohrbaugh T, Meltzer EO. A questionnaire to measure quality of life in adults with nocturnal allergic rhinoconjunctivitis. J Allergy Clin Immunol. 2003; 111: 484-490.

9. Verdalle $P$, Roquet $E$, Hor F, et al. Pituitary abscess. A rare complication of sinusitis. Rev Laryngol Otol Rhinol (Bord). 1997; 118 : 327-329.

10. Landgraf JM, Maunsell E, Speechley KN, et al. Canadian-French, German and UK versions of the Child Health Questionnaire: methodology and preliminary item scaling results. Qual Life Res. 1998; 7: 433-445.

11. Kay DJ, Rosenfeld RM. Quality of life for children with persistent sinonasal symptoms. Otolaryngol Head Neck Surg. 2003; 128: 17-26.

12. Piccirillo JF, Merritt MG, Jr, Richards ML. Psychometric and clinimetric validity of the 20-Item Sino-Nasal Outcome Test (SNOT20). Otolaryngol Head Neck Surg. 2002; 126: 41-47.

13. Anderson ER, Murphy MP, Weymuller EA Jr. Clinimetric evaluation of the Sinonasal Outcome Test-16. Student Research Award 1998. Otolaryngol Head Neck Surg. 1999; 121: 702-707

14. Gliklich RE, Hilinski JM. Longitudinal sensitivity of generic and specific health measures in chronic sinusitis. Qual Life Res. 1995; 4: 27-32.

15. Atlas SJ, Gallagher PM, Wu YA, et al. Development and validation of a new health-related quality of life instrument for patients with sinusitis. Qual Life Res. 2005; 14: 1375-1386.

16. Nathan RA, Santilli J, Rockwell W, Glassheim J. Effectiveness of immunotherapy for recurring sinusitis associated with allergic rhinitis as assessed by the Sinusitis Outcomes Questionnaire. Ann Allergy Asthma
Immunol. 2004; 92: 668-672

17. Petersen KD, Kronborg C, Gyrd-Hansen D, Dahl R, Larsen JN, Lowenstein H. Quality of life in rhinoconjunctivitis assessed with generic and disease-specific questionnaires. Allergy. 2008; 63: 284-291.

18. Feldmann H. History of diaphanoscopy. Pictures from the history of otorhinolaryngology, illustrated by instruments from the collection of the Ingolstadt German Medical History Museum. Laryngorhinootologie. 1998; 77: 297-304

19. Nelson HS, Rosloniec DM, McCall LI, Ikle D. Comparative performance of five commercial prick skin test devices. J Allergy Clin Immunol. 1993; 92: 750-756.

20. Engler DB, DeJarnatt AC, Sim TC, Lee JL, Grant JA. Comparison of the sensitivity and precision of four skin test devices. J Allergy Clin Immunol. 1992; 90(6 Pt 1): 985-991.

21. Crimi E, Gaffi D, Frittoli E, Borgonovo B, Burastero SE. Depletion of circulating allergen-specific Th2 T Iymphocytes after allergen exposure in asthma. J Allergy Clin Immunol. 1997; 99: 788-797.

22. Chinoy B, Yee E, Bahna SL. Skin testing versus radioallergosorbent testing for indoor allergens. Clin Mol Allergy. 2005; 3: 4.

23. Nizankowska-Mogilnicka E, Bochenek G, Mastalerz L, et al. EAACI/GA2LEN guideline: aspirin provocation tests for diagnosis of aspirin hypersensitivity. Allergy. 2007; 62 1111-1118.

24. Doty RL, Shaman P, Dann M. Development of the University of Pennsylvania Smell Identification Test: a standardized microencapsulated test of olfactory function. Physiol Behav. 1984; 32: 489-502.

25. Cain WS, Gent J, Catalanotto FA, Goodspeed RB. Clinical evaluation of olfaction. Am J Otolaryngol. 1983; 4: 252-256.

26. Briner HR, Simmen D. Smell diskettes as screening test of olfaction. Rhinology. 1999; 37: 145-148.

27. Wright HN. Characterization of olfactory dysfunction. Arch Otolaryngol Head Neck Surg. 1987; 113: 163-168.

28. Hendriks AP. Olfactory dysfunction. Rhinology. 1988; 26: 229-251.

29. Corwin J. Olfactory identification in hemodialysis: acute and chronic effects on discrimination and response bias. Neuropsychologia. 1989; 27: 513-522.

30. Takagi SF. A standardized olfactometer in Japan. A review over ten years. Ann N Y Acad Sci. 1987; 510: 113-118.

31. Murphy C, Schubert CR, Cruickshanks KJ, Klein BE, Klein R, Nondahl DM. Prevalence of olfactory impairment in older adults. Jama. 2002; 288: 2307-2312.

32. Doty RL, McKeown DA, Lee WW, Shaman P. A study of the test-retest reliability of ten olfactory tests. Chem Senses. 1995; 20: 645-656.

33. Robson AK, Woollons AC, Ryan J, Horrocks C, Williams S, Dawes PJ. Validation of the combined olfactory test. Clin Otolaryngol Allied Sci. 1996; 21: 512-518

34. Hummel T, Sekinger B, Wolf SR, Pauli E, Kobal G. 'Sniffin' sticks': olfactory perform- ance assessed by the combined testing of odor identification, odor discrimination and olfactory threshold. Chem Senses. 1997; 22: 39-52.

35. Renner B, Mueller CA, Dreier J, Faulhaber S, Rascher W, Kobal G. The candy smell test: a new test for retronasal olfactory performance. Laryngoscope. 2009; 119: 487-495.

36. Davidson TM, Murphy C. Rapid clinical evaluation of anosmia. The alcohol sniff test. Arch Otolaryngol Head Neck Surg. 1997; 123: 591-594.

37. Ahlskog JE, Waring SC, Petersen RC, et al. Olfactory dysfunction in Guamanian ALS, parkinsonism, and dementia. Neurology. 1998; 51: 1672-1677.

38. Kremer B, Klimek L, Mosges R. Clinical validation of a new olfactory test. Eur Arch Otorhinolaryngol. 1998; 255: 355-358.

39. Nordin S, Bramerson A, Liden E, Bende M. The Scandinavian Odor-Identification Test: development, reliability, validity and normative data. Acta Otolaryngol. 1998; 118: 226-234.

40. Zinreich SJ, Kennedy DW, Malat J, et al. Fungal sinusitis: diagnosis with CT and MR imaging. Radiology. 1988; 169: 439-444.

41. Trotier D, Bensimon JL, Herman P, Tran Ba Huy P, Doving KB, Eloit C. Inflammatory obstruction of the olfactory clefts and olfactory loss in humans: a new syndrome? Chem Senses. 2007; 32: 285-292.

42. Kobal G, Palisch K, Wolf SR, et al. A threshold like measure for the assessment of olfactory sensitivity: the "random" procedure. Eur Arch Otorhinolaryngol. 2001; 258: 168-172.

43. Hummel $T$, Konnerth CG, Rosenheim K Kobal G. Screening of olfactory function with a four-minute odor identification test: reliability, normative data, and investigations in patients with olfactory loss. Ann Otol Rhinol Laryngol. 2001; 110: 976-981.

44. Guilemany JM, Garcia-Pinero A, Alobid I, et al. Persistent allergic rhinitis has a moderate impact on the sense of smell, depending on both nasal congestion and inflammation. Laryngoscope. 2009; 119: 233-238.

45. McMahon C, Scadding GK. Le Nez du Vin-a quick test of olfaction. Clin Otolaryngol Allied Sci. 1996; 21: 278-280.

46. ATS/ERS recommendations for standardized procedures for the online and offline measurement of exhaled lower respiratory nitric oxide and nasal nitric oxide, 2005. Am J Respir Crit Care Med. 2005; 171: 912-930.

47. Bartley J, Fergusson W, Moody A, Wells AU, Kolbe J. Normal adult values, diurnal variation, and repeatability of nasal nitric oxide measurement. Am J Rhinol. 1999; 13: 401405.

48. Biewenga J, Stoop AE, Baker HE, et al. Nasal secretions from patients with polyps and healthy individuals, collected with a new aspiration system: evaluation of total protein and immunoglobulin concentrations. Ann Clin Biochem. 1991; 28 (Pt 3): 260-266.

49. Pipkorn U, Karlsson G, Enerback L. A brush method to harvest cells from the nasal mucosa for microscopic and biochemical analysis. J Immunol Methods. 1988; 112(1): 
$37-42$.

50. van Benten IJ, van Drunen CM, Koopman LP, et al. Age- and infection-related maturation of the nasal immune response in 0-2-yearold children. Allergy. 2005; 60: 226-232.

51. Meltzer EO, Orgel HA, Rogenes PR, Field EA. Nasal cytology in patients with allergic rhinitis: effects of intranasal fluticasone propionate. J Allergy Clin Immunol. 1994; 94 708-715.

52. Jalowayski AA, Walpita P, Puryear BA, Connor JD. Rapid detection of respiratory syncytial virus in nasopharyngeal specimens obtained with the rhinoprobe scraper. J Clin Microbiol. 1990; 28: 738-741.

53. Fokkens WJ, Vroom TM, Gerritsma V, Rijntjes E. A biopsy method to obtain high quality specimens of nasal mucosa. Rhinology. 1988; 26: 293-295.

54. Nathan RA, Eccles R, Howarth PH, Steinsvag SK, Togias A. Objective monitoring of nasal patency and nasal physiology in rhinitis. Allergy Clin Immunol. 2005; 115(3 Suppl 1): S442-459.

55. Benninger MS, Payne SC, Ferguson BJ, Hadley JA, Ahmad N. Endoscopically directed middle meatal cultures versus maxil- lary sinus taps in acute bacterial maxillary rhinosinusitis: a meta-analysis. Otolaryngol Head Neck Surg. 2006; 134: 3-9.

56. Cohen M, Kofonow J, Nayak JV, et al. Biofilms in chronic rhinosinusitis: a review. Am J Rhinol Allergy. 2009; 23: 255-260.

57. Storm van's Gravesande K, Omran H. Primary ciliary dyskinesia: clinical presentation, diagnosis and genetics. Ann Med. 2005; 37: 439449

58. Agu RU, Jorissen M, Willems T, Augustijns $P$, Kinget $R$, Verbeke N. In-vitro nasal drug delivery studies: comparison of derivatised, fibrillar and polymerised collagen matrixbased human nasal primary culture systems for nasal drug delivery studies. J Pharm Pharmacol. 2001; 53: 1447-1456.

59. Bavbek S, Dursun AB, Birben E, Kalayci O, Misirligil Z. Cellular allergen stimulation test with acetylsalicylic acid-lysine is not a useful test to discriminate between asthmatic patients with and without acetylsalicylic acid sensitivity. Int Arch Allergy Immunol. 2009; 149: 58-64.

60. Voter KZ, Ren CL. Diagnosis of cystic fibrosis Clin Rev Allergy Immunol. 2008; 35: 100106.
61. Moscato G, Siracusa A. Rhinitis guidelines and implications for occupational rhinitis. Curr Opin Allergy Clin Immunol. 2009; 9: 110-115.

62. Airaksinen L, Tuomi $T$, Vanhanen $M$, Voutilainen $\mathrm{R}$, Toskala E. Use of nasal provocation test in the diagnostics of occupational rhinitis. Rhinology. 2007; 45: 40-46.

University Hospitals Leuven Kapucijnenvoer 33 B-3000 Leuven Belgium

Tel: +32332342

Fax: +32 332335

E-mail: Peter.Hellings@uzleuven.be

\section{EAACI Focused Meeting SERI N 2013}

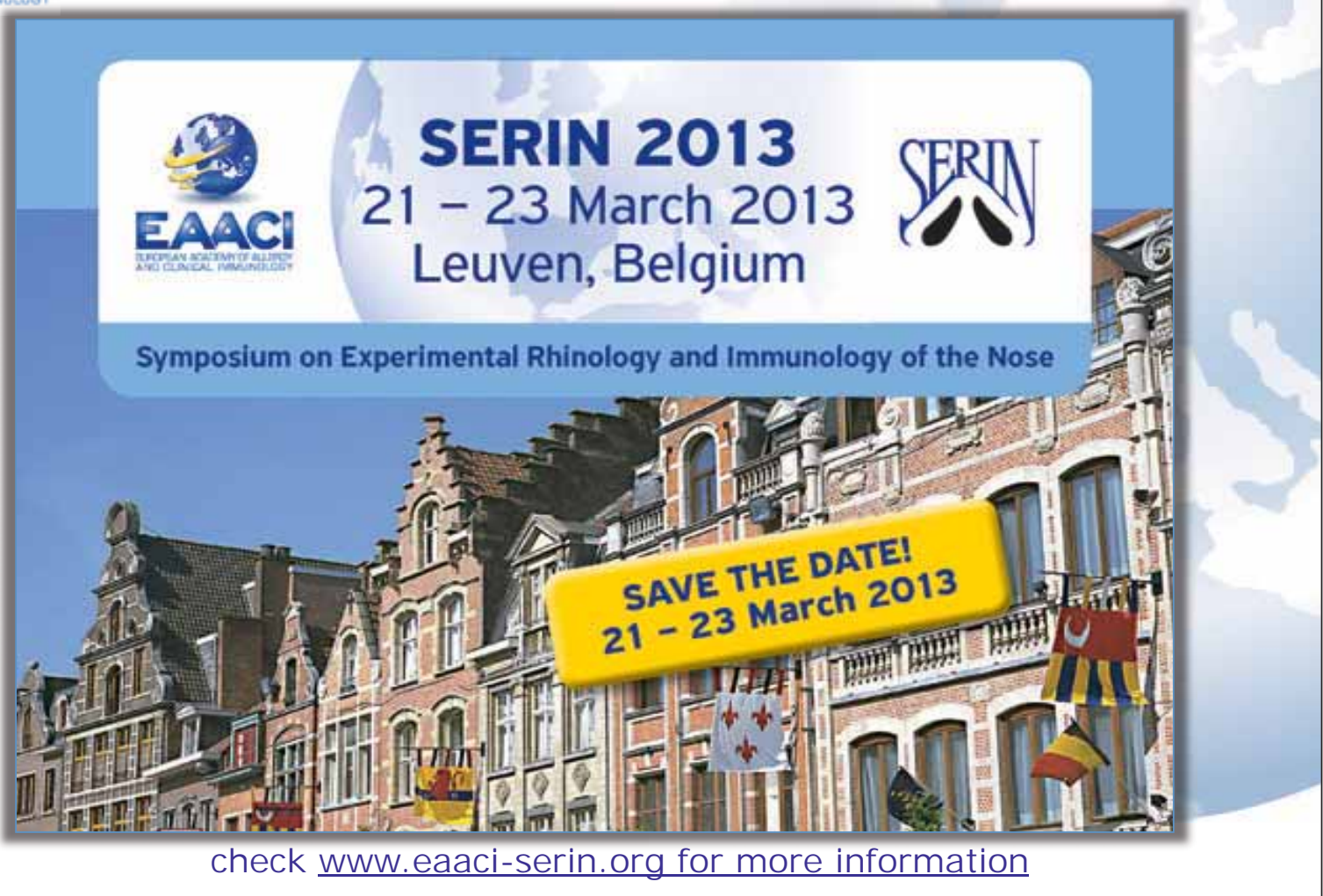

